\title{
Pathophysiology of postprandial hyperglycaemia in women with type 1 diabetes during pregnancy
}

\author{
H. R. Murphy • D. Elleri • J. M. Allen • J. Harris • D. Simmons • G. Rayman • \\ R. C. Temple • A. M. Umpleby • D. B. Dunger • A. Haidar • M. Nodale • \\ M. E. Wilinska $\cdot$ R. Hovorka
}

Received: 22 July 2011 / Accepted: 4 October 2011 / Published online: 12 November 2011

(C) Springer-Verlag 2011

\begin{abstract}
Aims/hypothesis Although maternal hyperglycaemia is associated with increased risk of adverse pregnancy outcome, the mechanisms of postprandial hyperglycaemia during pregnancy are poorly understood. We aimed to describe glucose turnover in pregnant women with type 1 diabetes, according to stage of gestation (early vs late gestation). Methods The rates of systemic glucose appearance $\left(R_{\mathrm{a}}\right)$ and glucose disposal $\left(R_{\mathrm{d}}\right)$ were measured in ten pregnant
\end{abstract}

H. R. Murphy $(\bowtie) \cdot$ D. Elleri $\cdot$ J. M. Allen $\cdot$ J. Harris $\cdot$

A. Haidar $\cdot$ M. Nodale $\cdot$ M. E. Wilinska $\cdot$ R. Hovorka

University of Cambridge Metabolic Research Laboratories and

NIHR Cambridge Biomedical Research Centre,

Institute of Metabolic Science,

Box 289, Addenbrooke's Hospital, Hills Road,

Cambridge CB2 0QQ, UK

e-mail: hm386@medschl.cam.ac.uk

D. Elleri · D. B. Dunger · M. E. Wilinska $\cdot$ R. Hovorka

Department of Paediatrics, University of Cambridge,

Hills Road,

Cambridge, UK

D. Simmons

Cambridge University Hospitals NHS Foundation Trust,

Cambridge, UK

G. Rayman

Diabetes Centre, Ipswich Hospital NHS Trust,

Ipswich, UK

R. C. Temple

Elsie Bertram Diabetes Centre, Norfolk and Norwich University

Hospital NHS Trust,

Norwich, UK

A. M. Umpleby

Postgraduate Medical School, University of Surrey,

Guildford, UK women with type 1 diabetes during early (12-16 weeks) and late (28-32 weeks) gestation. Women ate standardised meals - a starch-rich $80 \mathrm{~g}$ carbohydrate dinner and a sugarrich $60 \mathrm{~g}$ carbohydrate breakfast - and fasted between meals and overnight. Stable-label isotope tracers ([6,6- $\left.{ }^{2} \mathrm{H}_{2}\right]$ glucose and $\left[\mathrm{U}-{ }^{13} \mathrm{C}\right]$ glucose) were used to determine $R_{\mathrm{a}}, R_{\mathrm{d}}$ and glucose bioavailability. Closed-loop insulin delivery maintained stable glycaemic conditions.

Results There were no changes in fasting $R_{\mathrm{a}}(10 \pm 2$ vs $\left.11 \pm 2 \mu \mathrm{mol} \mathrm{kg}^{-1} \min ^{-1} ; p=0.32\right)$ or fasting $R_{\mathrm{d}}(11 \pm 2 \mathrm{vs}$ $\left.11 \pm 1 \mu \mathrm{mol} \mathrm{kg} \mathrm{kin}^{-1} ; p=0.77\right)$ in early vs late gestation. There was increased hepatic insulin resistance $(381 \pm 237$ vs $\left.540 \pm 242 \mu \mathrm{mol} \mathrm{kg} \mathrm{kg}^{-1} \mathrm{~min}^{-1} \times \mathrm{pmol} / \mathrm{l} ; p=0.04\right)$ and decreased peripheral insulin sensitivity $(0.09 \pm 0.04$ vs $0.05 \pm 0.02 \mu \mathrm{mol} \mathrm{kg}{ }^{-1} \mathrm{~min}^{-1}$ per pmol/ dinner, $0.11 \pm 0.05 \mathrm{vs}$ $0.07 \pm 0.03 \mu \mathrm{mol} \mathrm{kg} \mathrm{min}^{-1}$ per pmol/l breakfast; $p=0.002$ ) in late gestation. It also took longer for insulin levels to reach maximal concentrations (49 [37-55] vs 71 [52-108] min; $p=0.004)$ with significantly delayed glucose disposal (108 [87-125] vs 135 [110-158] min; $p=0.005)$ in late gestation. Conclusions/interpretation Postprandial glucose control is impaired by significantly slower glucose disposal in late gestation. Early prandial insulin dosing may help to accelerate glucose disposal and potentially ameliorate postprandial hyperglycaemia in late pregnancy.

\section{Trial registration: ISRCTN 62568875}

Funding: Diabetes UK Project Grant BDA 07/003551. H.R. Murphy is funded by a National Institute for Health Research (NIHR) research fellowship (PDF/08/01/036). Supported also by the Juvenile Diabetes Research Foundation (JDRF), Abbott Diabetes Care (Freestyle Navigator CGM and sensors free of charge), Medical Research Council Centre for Obesity and Related Metabolic Diseases and NIHR Cambridge Biomedical Research Centre. 
Keywords Type 1 diabetes $\cdot$ Pregnancy $\cdot$ Glucose $\cdot$ Glucose tracer

$\begin{array}{ll}\text { Abbreviations } & \\ \text { CSII } & \text { Continuous subcutaneous insulin infusion } \\ \text { EGP } & \text { Endogenous glucose production } \\ \text { IQR } & \text { Interquartile range } \\ \text { MCR } & \text { Metabolic clearance rate } \\ \text { NICE } & \text { National Institute for Health and } \\ & \text { Clinical Excellence } \\ R_{\mathrm{a}} & \text { Rate of appearance } \\ R_{\mathrm{a} \text { sugars }} & \text { Rate of appearance of simple } \\ & \text { carbohydrates } \\ R_{\mathrm{a} \text { total }} & \text { Total postprandial glucose appearance } \\ R_{\mathrm{d}} & \text { Rate of disposal } \\ R_{\mathrm{I}, \mathrm{EGP}} & \text { Hepatic insulin resistance } \\ S_{\mathrm{I}, \mathrm{PERI}} & \text { Peripheral insulin sensitivity } \\ t_{25 \%}, t_{50 \%}, t_{75} \% & \text { Time for } 25 \%, 50 \% \text { and } 75 \% \\ & \text { appearance/disappearance } \\ t_{\mathrm{max}} & \text { Time to maximum concentration } \\ & \text { in plasma } \\ \text { TTR } & \text { Tracer:tracee ratio }\end{array}$

\section{Introduction}

Maternal glucose is the primary metabolic substrate for fetal growth during pregnancy, both in healthy women and in women with diabetes. Data from healthy pregnant women suggest that the mother adapts to the increasing fetal demands for glucose by increasing both the total rate of appearance of glucose and the endogenous glucose production in late gestation [1]. Women with type 1 diabetes spend on average $8 \mathrm{~h}$ per day in hyperglycaemia in late gestation, with most hyperglycaemic excursions following meals [2]. As the maternal and fetal glucose pools are in equilibrium [3], with a rapid transfer of glucose to the fetus according to maternal glucose concentration [4], maternal hyperglycaemia is associated with an adverse pregnancy outcome, most commonly fetal growth acceleration and increased risk of large-for-gestational-age offspring [5-7]. This remains the most common complication of pregnancy in type 1 diabetes [8-10] and confers immediate risks of delivery complications and neonatal hypoglycaemia in addition to the longer-term risks of insulin resistance, obesity and type 2 diabetes [11-13].

After digestion, monosaccharides are transported into the portal vein, where the systemic appearance of glucose is determined by the balance between hepatic extraction and release into the systemic circulation. The postprandial glucose excursion is defined by interactions between total postprandial glucose appearance (from sugars and complex carbohydrates), endogenous glucose production (EGP) and glucose disposal. Defining the precise contribution of complex carbohydrate is methodologically difficult, requiring the intrinsic labelling of glucose in starch [14]. Hence, the precise mechanisms of postprandial hyperglycaemia for meals containing complex carbohydrates have not yet been elucidated.

The oral glucose isotope $\left[\mathrm{U}_{-}{ }^{13} \mathrm{C}\right]$ glucose traces mealderived sugars. Its use has provided insights into the appearance of meal-derived glucose for sugar-rich meals in healthy individuals $[15,16]$ and to a limited extent in those with type 1 diabetes $[17,18]$. The systemic glucose isotope $\left[6,6-{ }^{2} \mathrm{H}_{2}\right]$ glucose traces the rate of systemic appearance $\left(R_{\mathrm{a}}\right)$ and disposal $\left(R_{\mathrm{d}}\right)$ of glucose. This allows a calculation of EGP during fasting conditions and of total postprandial glucose appearance (the sum of postprandial glucose from sugars, complex carbohydrates and EGP) after meals, thereby providing clinically relevant data regarding the discrepancy between glucose appearance and disposal. Carbohydrate digestion rates and gastric emptying are complex, with both intra- and interindividual variability, and in people with type 1 diabetes are further influenced by pre-meal glucose control [19]. Pregnancy adds further challenges of tight postprandial glucose control targets $(<7.8 \mathrm{mmol} / \mathrm{l}$ at $1 \mathrm{~h})$ as well as dynamic alterations in EGP, insulin kinetics and gastric emptying [1, 20, 21].

Recent technological advances, in particular the accelerated development of closed-loop insulin delivery systems, have further highlighted the need for improved prandial algorithms $[22,23]$. Physiologically derived insulin algorithms would benefit from an accurate measurement of glucose turnover and insulin kinetics in pregnancy for women with type 1 diabetes. The aim of this study was to facilitate the development of improved prandial insulin algorithms by quantifying glucose turnover during fasting and postprandial conditions in pregnancy in women with type 1 diabetes. Values for $R_{\mathrm{a}}$ and $R_{\mathrm{d}}$ were quantified to document changes in glucose turnover according to stage of gestation (early vs late pregnancy) following an evening meal, overnight fast and breakfast meal. In addition, gestational changes in insulin resistance and insulin kinetics were investigated.

\section{Methods}

Study protocol Ten pregnant women with type 1 diabetes were admitted to the Wellcome Trust clinical research facility (Cambridge, UK) for $24 \mathrm{~h}$ on two separate occasions during early pregnancy (12-16 weeks) and late gestation (28-32 weeks). The protocol was approved by the Suffolk, Norfolk and Cambridgeshire research ethics committees, and all participants provided written informed consent. 
Study participants From March 2009 to March 2010, ten pregnant women (median age 31.1 [28.7-31.7] years, duration of diabetes 19 [13.5-24] years, weight 66.6 [64-73.9] kg, booking $\mathrm{HbA}_{1 \mathrm{c}}$ 6.9\% [6.2-8.0] and BMI $24.1[23.1-26.3] \mathrm{kg} / \mathrm{m}^{2}$ ) were recruited. All participants were non-smokers, and half were primiparous. Inclusion criteria were diagnosis of type 1 diabetes (WHO criteria) for at least 12 months, intensive insulin therapy (multiple daily injections or pump therapy) and a viable singleton pregnancy. Women with concomitant physical or psychological conditions, poor glycaemic control $\left(\mathrm{HbA}_{1 \mathrm{c}}>10 \%\right.$ [86 $\mathrm{mmol} / \mathrm{mol}]$ ), class II-III obesity (BMI $\geq 35 \mathrm{~kg} / \mathrm{m}^{2}$ ), insulin resistance (total daily insulin dose $\geq 1.5 \mathrm{U} / \mathrm{kg}$ ), impaired renal function, autonomic neuropathy and/or gastroparesis were excluded. For women on multiple daily injections $(n=5)$, basal insulin was withdrawn $24 \mathrm{~h}$ before admission and replaced with rapid-acting insulin analogue Aspart (Novo-Nordisk, Bagsvaerd, Denmark) delivered in three or four pre-meal boluses.

Study procedures At 13:00 hours, two intravenous sampling cannulae were inserted: one for obtaining venous blood samples and the other to infuse the glucoseappearance-mimicking glucose tracer $\left(\left[6,6-{ }^{2} \mathrm{H}_{2}\right]\right.$ glucose). A continuous subcutaneous insulin infusion (CSII) was commenced (Deltec Cozmo; Smiths Medical, St Paul, MN, USA) delivering the rapid-acting insulin analogue Aspart, with closed-loop insulin delivery used to maintain stable glycaemic conditions [22]. For women on CSII, their existing site was used, and for those previously on injection therapy, the insertion site was located on the inguinal region of the anterior abdominal wall. Prandial insulin boluses were not part of closed-loop insulin delivery; these were calculated by women according to their pre-meal capillary glucose measurement, the carbohydrate content of the meal and the insulin:carbohydrate ratio. All women were aiming for the National Institute for Health and Clinical Excellence (NICE) postprandial glycaemic control target of $<7.8 \mathrm{mmol} / \mathrm{l}$ at $1 \mathrm{~h} \mathrm{[21]}$. All boluses were administered by a research nurse immediately before meals using a standard bolus delivery pattern. Full details of the prandial boluses and total daily insulin doses in early and late gestation are described in Table 1.

At 16:00 hours, a primed intravenous infusion of $\left[6,6-{ }^{2} \mathrm{H}_{2}\right]$ glucose $(1 \mathrm{mg} / \mathrm{kg})$ was started and was continued until 12:00 the following day. The infusion rate of $\left[6,6-{ }^{2} \mathrm{H}_{2}\right]$ glucose remained constant when no changes in systemic glucose appearance were anticipated (16:00-18:00 and 02:00-07:00 hours). Infusion rates were increased following meal consumption: -10 to $0 \mathrm{~min} 100 \%, 0-10 \mathrm{~min}$ $125 \%, 10-20$ min $180 \%, 20-30$ min $240 \%$, 30-60 min $280 \%, 60-70 \min 270 \%, 70-80 \min 260 \%, 80-90 \mathrm{~min}$ $250 \%, 90-120 \min 240 \%, 120-150 \min 200 \%, 180$
$210 \min 180 \%$, 210-240 min 160\%, 240-270 min 140\%, 270-300 min $120 \%, 300-330$ min $110 \%$, 330-360 min $105 \%$ and $360-450 \mathrm{~min} 100 \%$ to mimic systemic glucose appearance in postprandial conditions and reduce swings in the tracer:tracee ratio (TTR).

At 18:00 hours, the women ate an evening meal. This was followed by an overnight fast (drinking water being permitted) until the following morning, when a breakfast meal was provided at 07:00 hours. The study ended at 12:00 on day 2 .

Study meals The evening meal was penne pasta with a tomato-based vegetable sauce and grated cheese topping, freshly prepared by the study dietitian. It contained $2,497 \mathrm{~kJ}(602 \mathrm{kcal}): 80 \mathrm{~g}$ carbohydrate $(52 \%$ of total energy), $11 \mathrm{~g}$ sugars, $4 \mathrm{~g}$ fat (16\%) and $9 \mathrm{~g}$ protein (32\%). Breakfast, which comprised orange juice and two slices of wholegrain toast with butter and jam, contained 1,489 kJ (356 kcal): $57 \mathrm{~g}$ carbohydrate $(62 \%), 25 \mathrm{~g}$ sugars, $11 \mathrm{~g}$ fat $(29 \%)$ and $7.6 \mathrm{~g}$ protein $(9 \%)$. A meal glucose isotope tracer, $0.85 \mathrm{~g}\left[\mathrm{U}_{-}^{13} \mathrm{C}\right]$ glucose, to trace meal-derived sugars, was divided into two equal parts and dissolved in jelly (Hartley's sugar-free raspberry jelly; Premier Foods Ltd, St Albans, UK) in two $5 \mathrm{ml}$ plastic cups, frozen and swallowed intact $5 \mathrm{~min}$ and $10 \mathrm{~min}$ following the start of each meal. All meals were completed within $20 \mathrm{~min}$ of commencement.

Laboratory assays Venous samples were obtained for measurement of plasma glucose concentration (Yellow Springs Instrument YSI 2300 STAT Plus Analyser; Farnborough, UK). Samples were centrifuged immediately with plasma kept on ice and stored at $-80^{\circ} \mathrm{C}$ prior to further analyses. Plasma insulin concentration was measured by an immunochemiluminometric assay (Invitron, Monmouth, $\mathrm{UK}$; intra-assay CV 4.7\%, interassay CV 7.2-8.1\%). Glucose isotope enrichment was measured using the trimethyl silyl- $O$-methyloxime derivative, by GC-MS (Agilent 5975 C inert XL EI/CI MSD; Agilent Technologies, Wokingham, UK). Ions monitored were $\mathrm{m} / \mathrm{z} 319.2, \mathrm{~m} / \mathrm{z} 321.2$ and $\mathrm{m} / \mathrm{z} 323.2$ for glucose, $\left[6,6-{ }^{2} \mathrm{H}_{2}\right]$ glucose and $\left[\mathrm{U}^{13}{ }^{13} \mathrm{C}\right]$ glucose, respectively, as previously described [24, 25]. Samples for the determination of background glucose isotope enrichment were taken at 15:50, 15:55 and 16:00 hours and for pre-meal glucose enrichment at 15, 10, 5 and 0 min before meals. Plasma glucose, insulin and glucose enrichment were measured at $10 \mathrm{~min}$ intervals for $90 \mathrm{~min}$ after meals and at 15-30 min intervals at other times.

Calculations The glucose turnover calculations were based on the maximum likelihood method [26] modified for a Bayesian implementation in WinBUGS (MRC Biostatistics Unit, Cambridge, UK) version 1.4 [27] and utilising the 


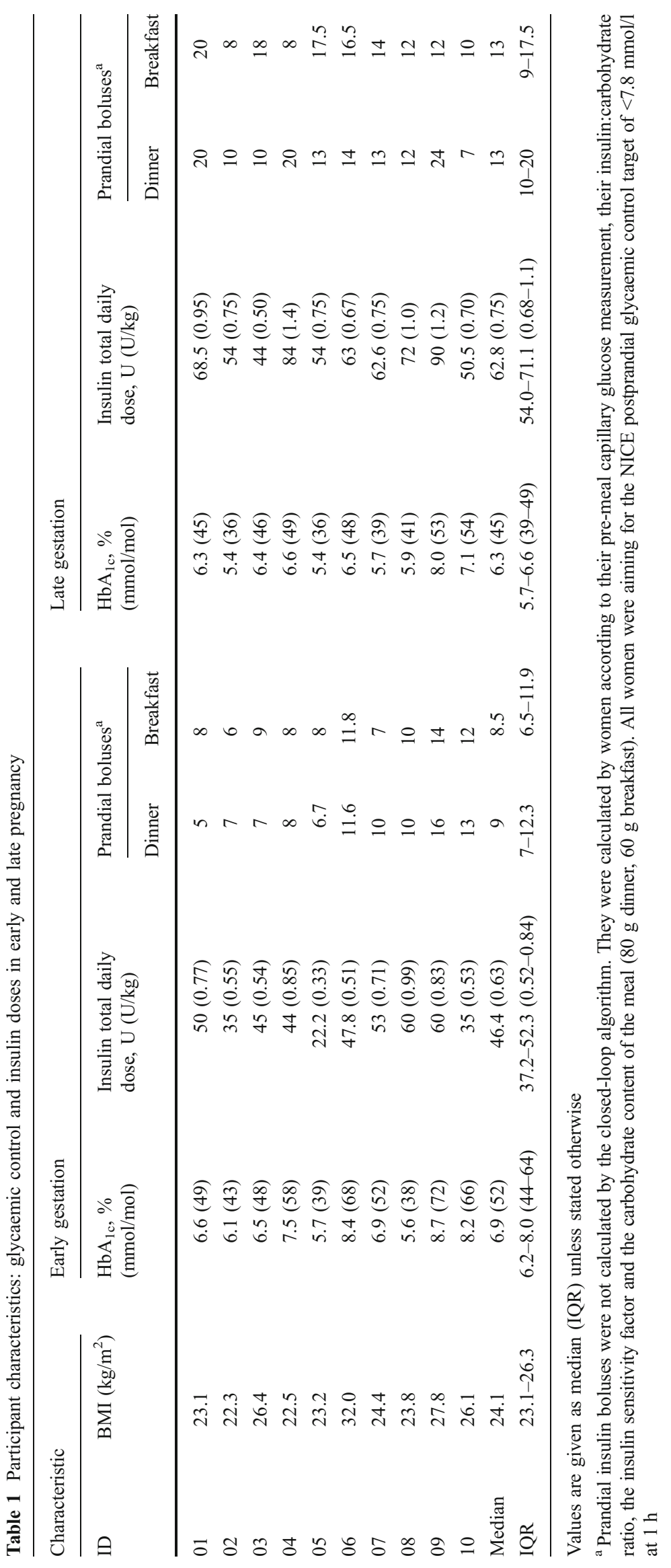


WBDiff interface (MRC Biostatistics Unit) version 1.9.4 to implement the differential equations representing the twocompartment Mari model [28].

We calculated $R_{\mathrm{a}}, R_{\mathrm{d}}$, and $R_{\mathrm{a} \text { sugars }} . R_{\mathrm{a}}$ represents the total rate of glucose appearance in the systemic circulation. During overnight fasting conditions (02:00-07:00 hours), the $R_{\mathrm{a}}$ reflects EGP. During postprandial conditions $(5 \mathrm{~h}$ post-meal), $R_{\text {a total }}$ reflects total postprandial glucose appearance, representing the sum of all meal-derived glucose (sugars and complex carbohydrates) and postprandial EGP. $R_{\mathrm{a}}$ and $R_{\mathrm{d}}$ were calculated by analysis of $\left[6,6-{ }^{2} \mathrm{H}_{2}\right]$ glucose. $R_{\mathrm{a}}$ sugars represents the rate of appearance of simple carbohydrates and was calculated from $\left[6,6-{ }^{2} \mathrm{H}_{2}\right]$ glucose and $\left[\mathrm{U}_{-}{ }^{13} \mathrm{C}\right]$ glucose utilising the dual-tracer approach [26].

The bioavailability of $\left[\mathrm{U}^{13} \mathrm{C}\right]$ glucose represented the total bioavailability of meal-derived sugars. The time to reach $25 \%, 50 \%$ and $75 \%$ of cumulative $R_{\text {a sugars }}$ reflects the rate of glucose appearance from meal-derived sugars from the start of meal to $5 \mathrm{~h}$ later $\left(R_{\mathrm{a} \text { sugars }} t_{25 \%}, R_{\mathrm{a} \text { sugars }} t_{50 \%}\right.$ and $R_{\mathrm{a}}$ sugars $\left.t_{75 \%}\right)$. Similarly, the rate of total postprandial glucose appearance was quantified by the time to reach $25 \%, 50 \%$ and $75 \%$ of cumulative $R_{\text {a total }}$ over the $5 \mathrm{~h}$ postprandial period.

Insulin resistance and kinetics Hepatic insulin resistance $\left(R_{\mathrm{I}, \mathrm{EGP}}\right)$ was calculated as the product of fasting $R_{\mathrm{a}}$ and fasting plasma insulin concentration between 02:00 and 07:00 hours. Peripheral insulin sensitivity $\left(S_{\text {I,PERI }}\right)$ was calculated as average $R_{\mathrm{d}}$ above fasting during the $5 \mathrm{~h}$ after meal divided by average plasma insulin above fasting during the first $5 \mathrm{~h}$ after each meal.

Insulin kinetics were assessed using a two-compartment absorption chain, model 1 in Wilinska et al. [29] with an impulse response function defined as $y=t \times$ $\exp \left(-t / t_{\max }\right) /\left(t_{\max } \times t_{\max } \times \mathrm{MCR}\right)$ where $t_{\max }$ is time to maximum insulin concentration in plasma, and MCR is the metabolic clearance rate of insulin. The plasma insulin concentration is obtained by convolution $y \times u$, where $u$ is the insulin delivery. To account for time-varying residual insulin appearance, a linear component was added to the model-derived plasma insulin concentration in the form of $\mathrm{a} \times t+\mathrm{b}$. The model parameters $t_{\max }, \mathrm{MCR}$, a and $\mathrm{b}$ were estimated for the 5-h-long dinner and breakfast periods employing a non-linear, weighted, least-squares approach using SAAM II version 1.2.1 software (SAAM Institute, Seattle, WA, USA) with weights reciprocal to the square of the measured plasma insulin concentration.

Statistics The effects of the two meals (dinner and breakfast) and the stage of gestation (early and late) were contrasted using ANOVA with adjustment for maternal characteristics (age, duration of diabetes, $\mathrm{HbA}_{1 \mathrm{c}}$ and $\mathrm{BMI}$ at booking). To contrast only the effect of gestation (early vs late), paired $t$ tests were used. Data were $\log$-transformed where appropriate to achieve normality. Values are given as mean $\pm \mathrm{SD}$, and if not normally distributed as median and interquartile range (IQR). Analyses were conducted on SPSS Version 15 (SPSS, Chicago, IL, USA). Values of $p<0.05$ were considered statistically significant.

\section{Results}

Glucose control Closed-loop insulin delivery was used to achieve stable and comparable glycaemic conditions prior to meal consumption and throughout both study visits [22]. Satisfactory glyacemic control was maintained with no
Fig. 1 Plasma glucose levels in early and late gestation. Data are median and IQR, dark grey for early gestation and light grey for late gestation

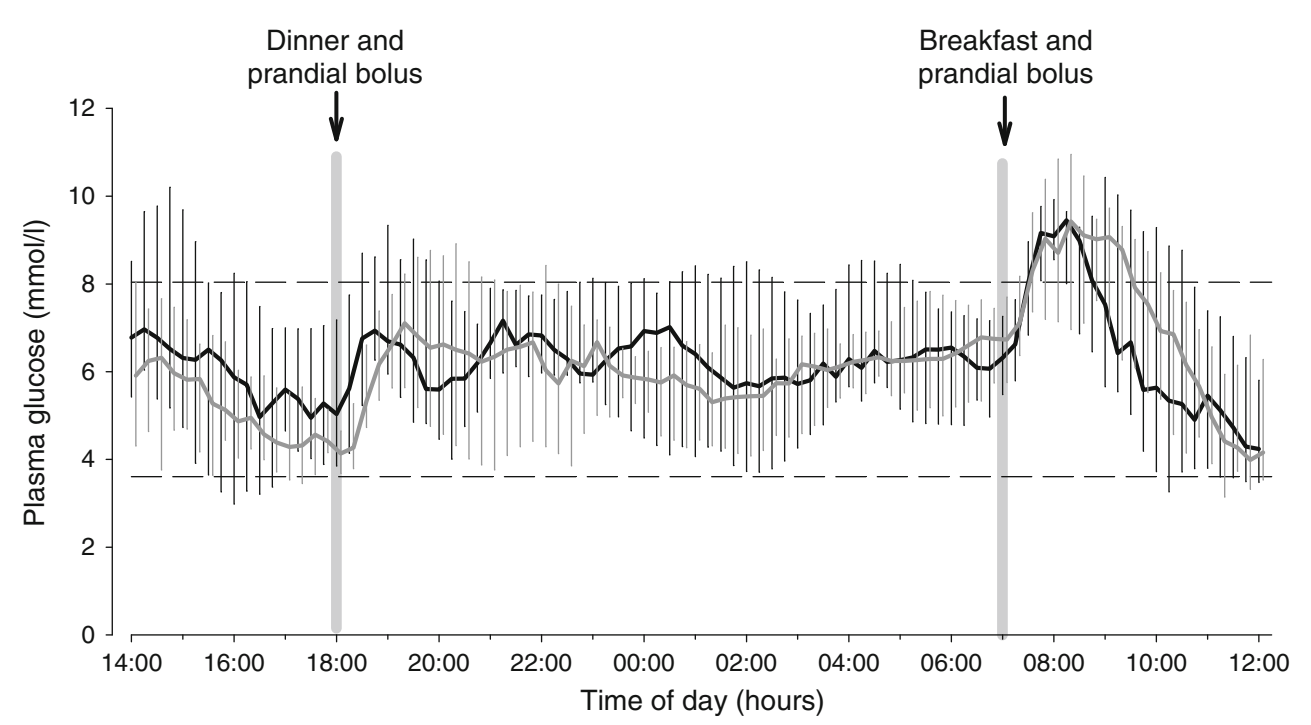


Fig. 2 Plasma insulin concentration in early and late gestation. Data are median and IQR, dark grey for early gestation and light grey for late gestation

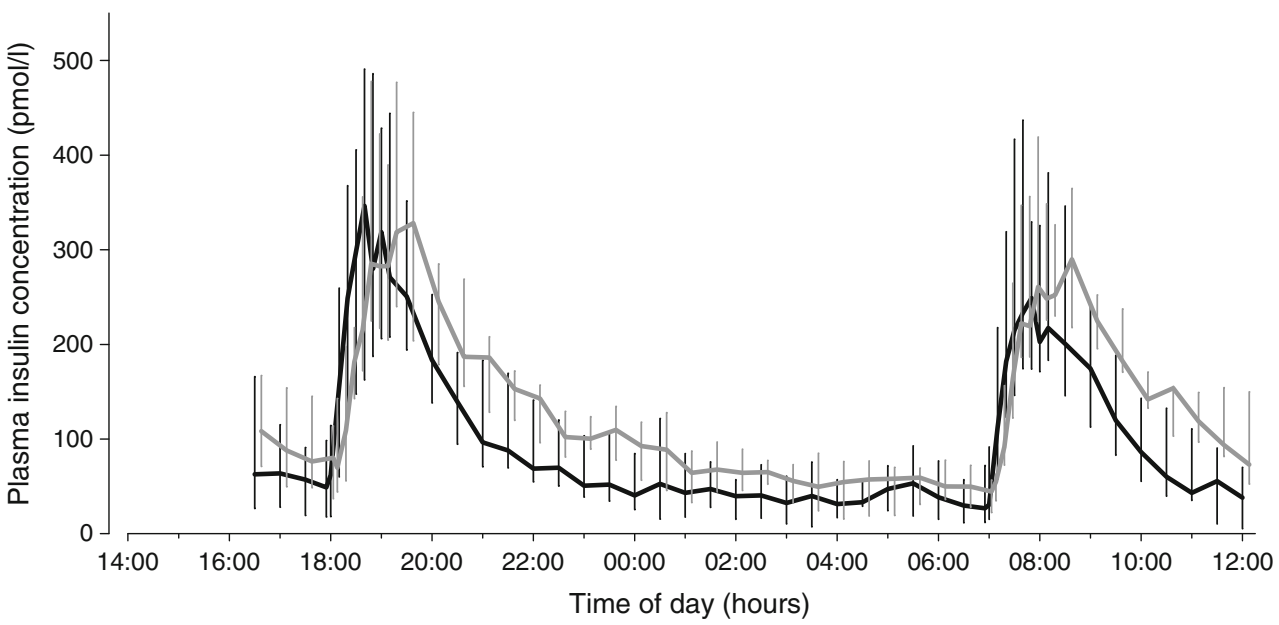

significant differences between visits (Fig. 1). Plasma glucose levels were comparable in early (median $6.5 \mathrm{mmol} / \mathrm{l}$, IQR 5.6-8.6) and in late (median $7.0 \mathrm{mmol} / \mathrm{l}$, IQR $6.1-7.8 ; \mathrm{p}=0.72$ ) gestation. Stable pre-meal plasma glucose levels, required for accurate evaluation of glucose enrichment, were obtained (early vs late gestation median [IQR] glucose, pre-dinner $4.9 \mathrm{mmol} / 1$ [3.8-7.1] vs 5.7 [4.2-7.8] and pre-breakfast $6.1 \mathrm{mmol} / 1$ [5.3-7.0] vs $6.6 \mathrm{mmol} / 1[5.7-7.4] ; p=0.50)$.

Insulin requirements Prandial insulin boluses (Table 1) increased significantly with advancing gestation ( $p=$ $0.0001)$. There was also a trend to increased basal insulin infusion rate $(0.55 \pm 0.26$ vs $0.67 \pm 0.29 \mathrm{U} / \mathrm{h} ; p=0.15)$ and increased plasma insulin concentration (median [IQR], 99 [73-138] vs 129 [112-191] pmol/1; $p=0.07)$ in late gestation (Fig. 2).

Glucose enrichment The stable-label tracer approach permitted the measurement of the systemic $R_{\mathrm{a}}$ of glucose. In postprandial conditions, $R_{\mathrm{a}}$ total incorporates total meal- derived glucose (sugars and complex carbohydrates) and postprandial EGP. The $\left[\mathrm{U}_{-}{ }^{13} \mathrm{C}\right]$ glucose TTR for sugars was indistinguishable between early and late gestation, with more intraindividual and gestational variability in $\left[6,6-{ }^{2} \mathrm{H}_{2}\right]$ glucose TTR for glucose appearance from total carbohydrate (Fig. 3).

Glucose appearance and turnover in fasting conditions The rates of fasting glucose appearance and disposal during early and late gestation are shown in Table 2 and Figs 4 and 5. During the overnight period (02:00-07:00 hours), there was an increase in absolute EGP (early vs late gestation fasting $R_{\mathrm{a}} 724 \pm 151$ vs $\left.844 \pm 184 \mu \mathrm{mol} / \mathrm{min} ; p=0.04\right)$, which did not persist when corrected for maternal weight gain $(10 \pm 2$ vs $\left.11 \pm 2 \mu \mathrm{mol} \mathrm{kg} \mathrm{kg}^{-1} \min ^{-1} ; p=0.3\right)$. There were no gestational changes in the absolute or weight-corrected overnight glucose disposal rates (early vs late gestation fasting $R_{\mathrm{d}} 11 \pm 2$ vs $11 \pm 1 \mu \mathrm{mol} \mathrm{kg} \mathrm{min}^{-1} ; p=0.8$ ). Nonetheless, higher insulin doses and plasma insulin concentrations were required to achieve a steady state in late gestation.
Fig. 3 TTR in early and late gestation. Data are median and IQR, dark grey for early gestation and light grey for late gestation. Dashed lines represent the $\left[6,6-{ }^{2} \mathrm{H}_{2}\right]$ glucose tracer, tracing total absorption of carbohydrate $\left(R_{\mathrm{a} \text { meal }}+\mathrm{EGP}\right)$ and solid lines the $\left[\mathrm{U}_{-}{ }^{13} \mathrm{C}\right] \mathrm{glucose}$ tracer, tracing sugars

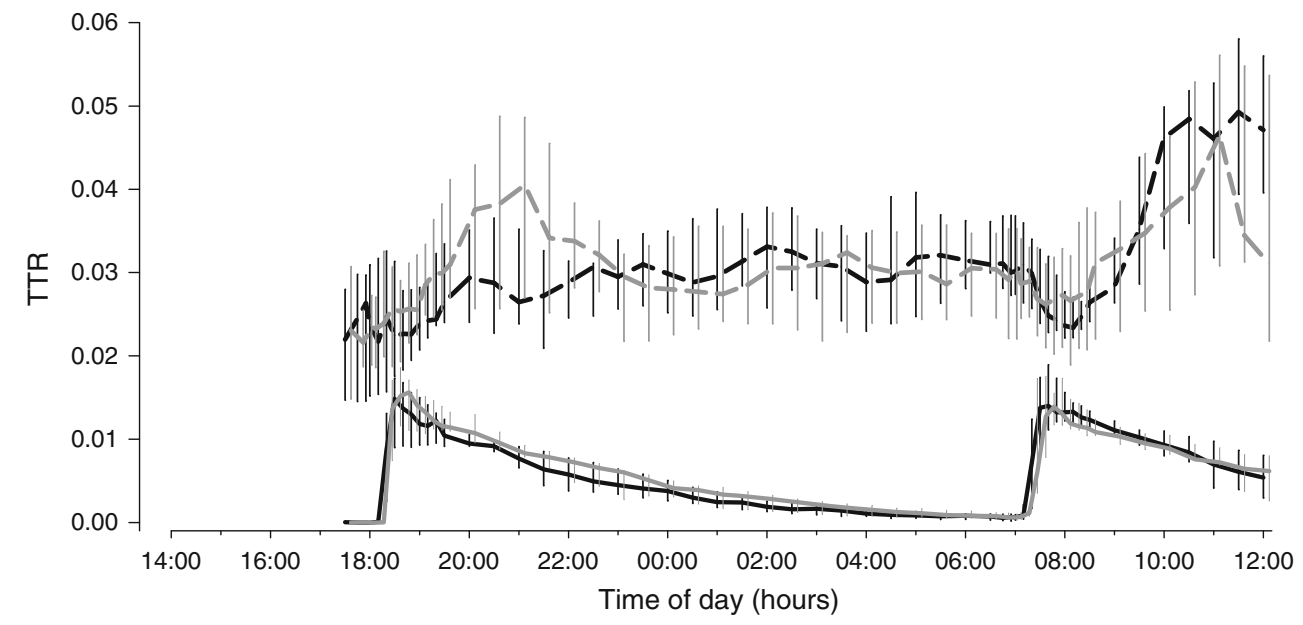


Table 2 Glucose turnover, insulin sensitivity and insulin kinetics during early and late gestation in type 1 diabetes pregnancy

\begin{tabular}{|c|c|c|c|c|c|c|}
\hline \multirow[t]{2}{*}{ Variable } & \multirow[t]{2}{*}{ Units } & \multirow[t]{2}{*}{ Meal } & \multirow{2}{*}{$\begin{array}{l}\text { Visit } 1 \\
\text { Mean } \pm \text { SD }\end{array}$} & \multirow{2}{*}{$\begin{array}{l}\text { Visit } 2 \\
\text { Mean } \pm \text { SD }\end{array}$} & \multicolumn{2}{|c|}{ ANOVA $p$ value ${ }^{a}$} \\
\hline & & & & & Visit & Meal \\
\hline \multirow{2}{*}{$\begin{array}{l}\text { Fasting } R_{\mathrm{a}} \text { (endogenous } \\
\text { glucose production) }{ }^{\mathrm{b}}\end{array}$} & Per kg $\left(\mu \mathrm{mol} \mathrm{kg}{ }^{-1} \min ^{-1}\right)$ & & $10 \pm 2$ & $11 \pm 2$ & 0.3 & - \\
\hline & Absolute $(\mu \mathrm{mol} / \mathrm{min})$ & & $724 \pm 151$ & $844 \pm 184$ & 0.04 & - \\
\hline \multirow[t]{2}{*}{ Fasting $R_{\mathrm{d}}^{\mathrm{b}}$} & Per kg $\left(\mu \mathrm{mol} \mathrm{kg}{ }^{-1} \min ^{-1}\right)$ & & $11 \pm 2$ & $11 \pm 1$ & 0.8 & - \\
\hline & Absolute $(\mu \mathrm{mol} / \mathrm{min})$ & & $737 \pm 137$ & $789 \pm 103$ & 0.2 & - \\
\hline Surrogate marker of $R_{\mathrm{I}, \mathrm{EGP}}$ & $\mu \mathrm{mol} \mathrm{kg}{ }^{-1} \min ^{-1} \times \mathrm{pmol} / 1$ & & $381 \pm 237$ & $540 \pm 242$ & 0.04 & - \\
\hline \multirow[t]{2}{*}{ Surrogate marker of $S_{\mathrm{I}, \mathrm{PERI}}$} & $\mu \mathrm{mol} \mathrm{kg}{ }^{-1} \min ^{-1}$ per pmol/1 & Dinner & $0.09 \pm 0.04$ & $0.05 \pm 0.02$ & 0.002 & 0.04 \\
\hline & & Breakfast & $0.11 \pm 0.05$ & $0.07 \pm 0.03$ & & \\
\hline \multirow[t]{2}{*}{ Bioavailability of sugars } & $\%$ & Dinner & $102 \pm 6$ & $97 \pm 9$ & 0.4 & 1.0 \\
\hline & & Breakfast & $101 \pm 8$ & $99 \pm 8$ & & \\
\hline \multirow[t]{6}{*}{$R_{\mathrm{a} \text { sugars }}$} & $R_{\text {a sugars }} t_{25 \%}(\min )$ & Dinner & $31 \pm 11$ & $25 \pm 5$ & 0.1 & 0.3 \\
\hline & & Breakfast & $27 \pm 8$ & $24 \pm 9$ & & \\
\hline & $R_{\mathrm{a} \text { sugars }} t_{50 \%}(\mathrm{~min})$ & Dinner & $64 \pm 29$ & $51 \pm 20$ & 0.3 & 0.005 \\
\hline & & Breakfast & $44 \pm 16$ & $35 \pm 12$ & & \\
\hline & $R_{\mathrm{a} \text { sugars }} t_{75 \%}(\mathrm{~min})$ & Dinner & $123 \pm 46$ & $125 \pm 52$ & 0.6 & 0.003 \\
\hline & & Breakfast & $76 \pm 32$ & $78 \pm 41$ & & \\
\hline \multirow{6}{*}{$\begin{array}{l}\text { Postprandial glucose } \\
\text { appearance } R_{\mathrm{a} \text { total }}\end{array}$} & $R_{\text {a meal }} t_{25 \%}(\min )$ & Dinner & $51 \pm 10$ & $49 \pm 15$ & 0.7 & $<0.0001$ \\
\hline & & Breakfast & $34 \pm 8$ & $28 \pm 19$ & & \\
\hline & $R_{\text {a meal }} t_{50 \%}(\min )$ & Dinner & $109 \pm 24$ & $97 \pm 39$ & 0.6 & $<0.0001$ \\
\hline & & Breakfast & $58 \pm 18$ & $52 \pm 33$ & & \\
\hline & $R_{\text {a meal }} t_{75 \%}(\min )$ & Dinner & $168 \pm 30$ & $178 \pm 49$ & 0.5 & $<0.0001$ \\
\hline & & Breakfast & $88 \pm 34$ & $88 \pm 54$ & & \\
\hline \multirow[t]{6}{*}{ Postprandial $R_{\mathrm{d}}$} & $R_{\mathrm{d}} t_{25 \%}(\mathrm{~min})$ & Dinner & $70 \pm 14$ & $85 \pm 22$ & 0.02 & 0.1 \\
\hline & & Breakfast & $64 \pm 8$ & $75 \pm 15$ & & \\
\hline & $R_{\mathrm{d}} t_{50 \%}(\mathrm{~min})$ & Dinner & $112 \pm 22$ & $142 \pm 34$ & 0.003 & 0.07 \\
\hline & & Breakfast & $103 \pm 17$ & $125 \pm 21$ & & \\
\hline & $R_{\mathrm{d}} t_{75 \%}(\mathrm{~min})$ & Dinner & $170 \pm 32$ & $208 \pm 33$ & 0.001 & 0.03 \\
\hline & & Breakfast & $150 \pm 38$ & $186 \pm 24$ & & \\
\hline \multirow[t]{2}{*}{ Insulin MCR } & $\mathrm{ml} \mathrm{kg}{ }^{-1} \min ^{-1}$ & Dinner & $25 \pm 3$ & $24 \pm 11$ & 0.4 & 0.5 \\
\hline & & Breakfast & $30 \pm 9$ & $24 \pm 11$ & & \\
\hline \multirow[t]{2}{*}{ Insulin $t_{\max }$} & $\min$ & Dinner & $53 \pm 13$ & $79 \pm 33$ & 0.0002 & 0.4 \\
\hline & & Breakfast & $46 \pm 10$ & $78 \pm 34$ & & \\
\hline
\end{tabular}

${ }^{a}$ ANOVA was adjusted for baseline differences in maternal age, duration of diabetes, $\mathrm{HbA}_{1 \mathrm{c}}$ and $\mathrm{BMI}$

${ }^{\mathrm{b}} R_{\mathrm{a}}$ and $R_{\mathrm{d}}$ were determined from 02:00 to 07:00 hours

Insulin resistance There were gestational increases in $R_{\mathrm{I}, \mathrm{EGP}}$ (early vs late gestation $381 \pm 237$ vs $540 \pm$ $\left.242 \mu \mathrm{mol} \mathrm{kg}{ }^{-1} \mathrm{~min}^{-1} \times \mathrm{pmol} / 1 ; p=0.04\right)$. There was also a decreased $S_{\mathrm{I} \text {,PERI }}$ in late gestation (early vs late gestation dinner $0.09 \pm 0.04$ vs $0.05 \pm 0.02 \mu \mathrm{mol} \mathrm{kg} \mathrm{min}^{-1}$ per pmol/1 $[p=0.002]$ and breakfast $0.11 \pm 0.05$ vs $0.07 \pm 0.03 \mu \mathrm{mol}$ $\mathrm{kg}^{-1} \mathrm{~min}^{-1}$ per pmol/1 $\left.[p=0.004]\right)$.

Postprandial glucose appearance Glucose appearance in postprandial conditions is shown in Table 2. The bioavailability of simple carbohydrates was unchanged during pregnancy ( $102 \pm 6$ vs $97 \pm 9 \% ; p=0.4)$, although differences in meal composition led to a significantly more rapid appearance of glucose after breakfast (Fig. 4a) than after dinner $\left(p=0.005\right.$ and $p<0.0001$ for $R_{\mathrm{a}}$ sugars and $R_{\mathrm{a}}$ total, respectively). However, gestation did not affect the rate or timing of the postprandial $R_{\mathrm{a}}$ (early vs late gestation dinner $R_{\text {a total }} t_{50 \%} \quad 109 \pm 24$ vs $97 \pm 39$ min and breakfast $R_{\text {a total }}$ $t_{50 \%} 58 \pm 18$ vs $52 \pm 33 \mathrm{~min} ; p=0.6$ ). While there are no quantitative differences in postprandial glucose appearance over the $5 \mathrm{~h}$ period, in early pregnancy there are two distinct peaks of glucose appearance after dinner, with a second peak between 2 and $4 \mathrm{~h}$ after dinner (Fig. $4 \mathrm{~b}$ ). This second peak effect is less pronounced in late pregnancy and did not occur after breakfast, with its higher proportion of simple carbohydrates. 
Fig. 4 Systemic $R_{\mathrm{a}}$ of glucose during early and late gestation.

a $R_{\text {a sugars }} ; \mathbf{b} R_{\text {a total }}$. During postprandial conditions $(5 \mathrm{~h}$ post-meal), $R_{\mathrm{a} \text { total }}$ reflects total postprandial glucose appearance, representing the sum of all meal-derived glucose (sugars and complex carbohydrates) and postprandial EGP. Data are median and IQR, dark grey for early gestation and light grey for late gestation
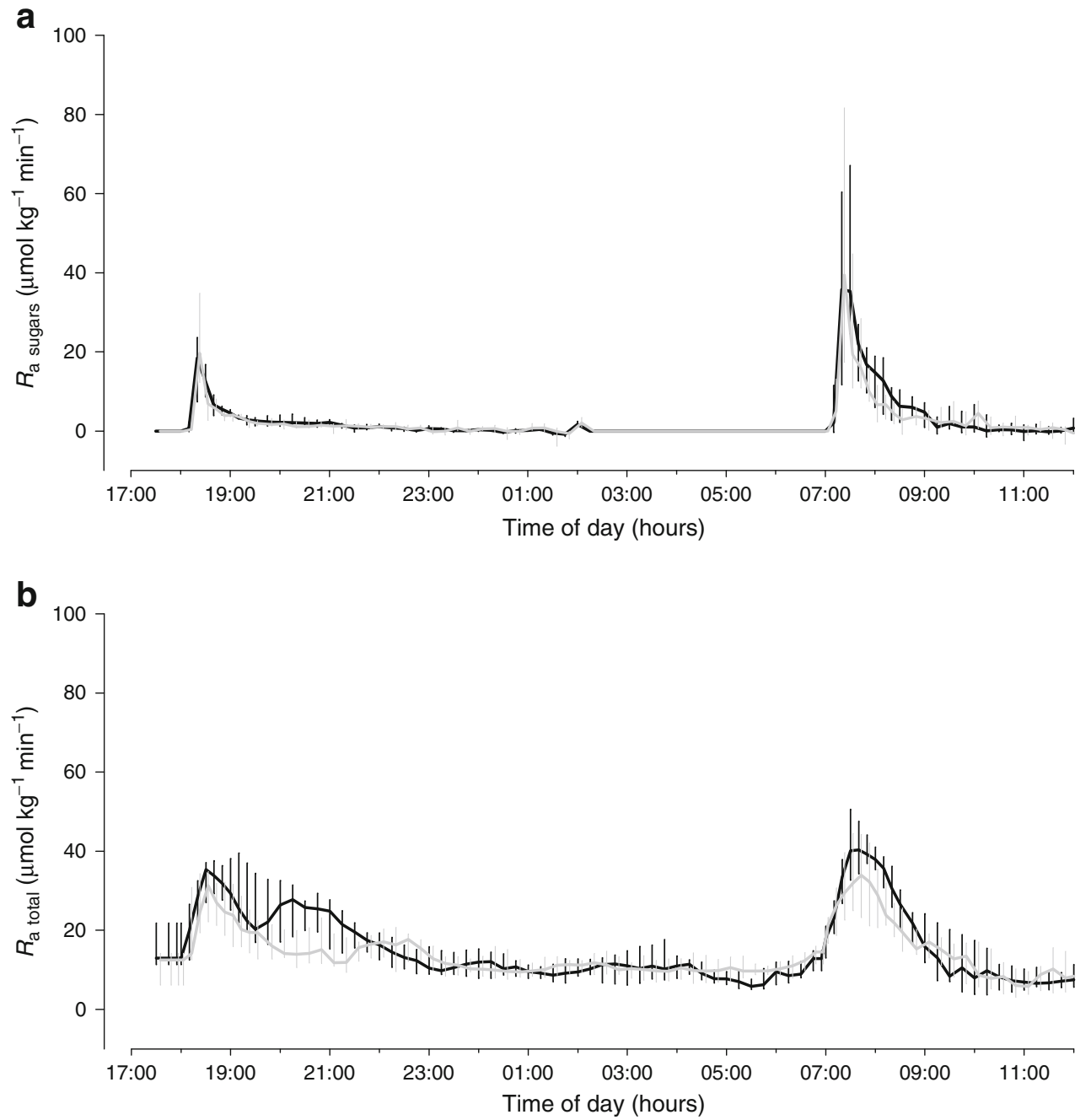

Postprandial glucose disposal Although the fasting and postprandial glucose appearance rates were unchanged, there were significant delays in postprandial glucose disposal (Table 2, Fig. 5), after both dinner and breakfast, in late gestation (early vs late dinner $R_{\mathrm{d}} t_{50 \%} 112 \pm 22$ vs $142 \pm 34 \mathrm{~min}$, and breakfast $R_{\mathrm{d}} t_{50 \%} 103 \pm 17$ vs $125 \pm 21 \mathrm{~min} ;$ $p=0.003)$. The delayed postprandial glucose disposal could not be attributed to increased insulin clearance
Fig. 5 Systemic glucose $R_{\mathrm{d}}$ during early and late gestation. Data are median and IQR, dark grey for early gestation and light grey for late gestation

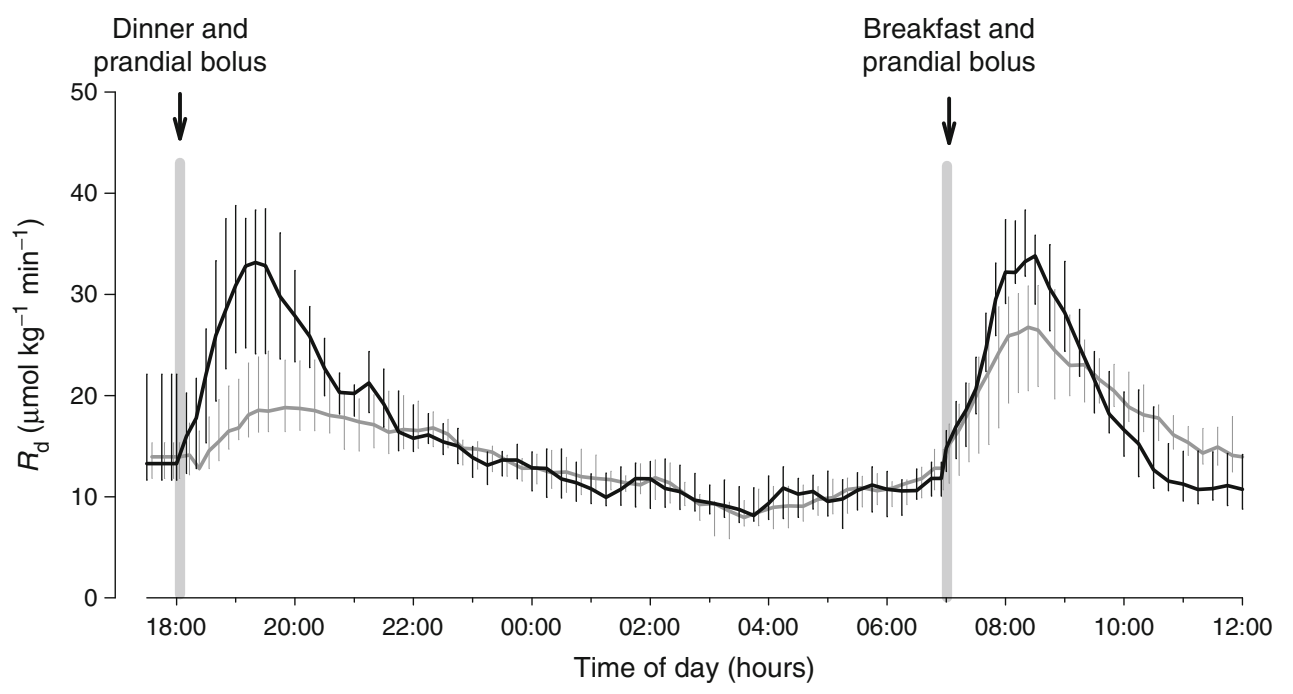



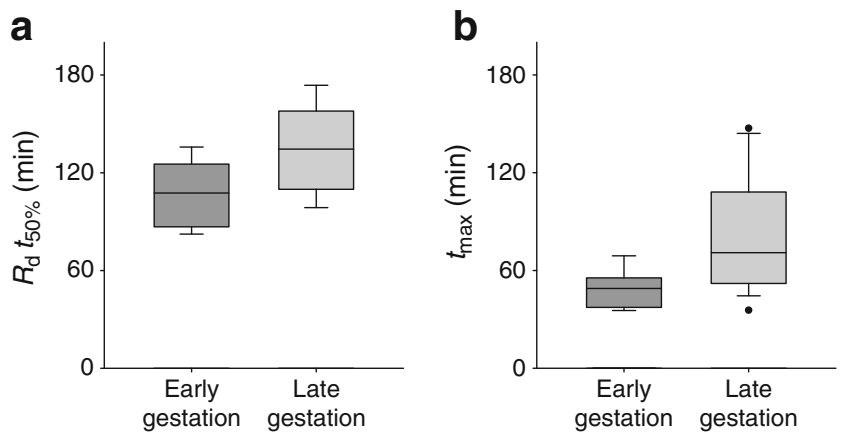

Fig. 6 Glucose disposal and plasma insulin concentration $t_{\max }$ during early and late gestation. a Boxplots depicting $R_{\mathrm{d}} t_{50 \%}$ for the dinner and breakfast meals combined. b Boxplots depicting insulin $t_{\max }$ for the dinner and breakfast meals combined. Data are median, IQR and range (including outliers), dark grey for early gestation and light grey for late gestation

as the metabolic clearance rate of insulin was unchanged in late gestation $(p=0.4)$. To examine the possibility of delayed insulin absorption from the subcutaneous infusion site, we calculated insulin $t_{\text {max }}$. Strikingly, it took significantly longer for insulin levels to reach maximal concentrations in late gestation (early vs late insulin $t_{\max }$ dinner $53 \pm 13$ vs $79 \pm 33 \mathrm{~min}$ and breakfast $46 \pm 10$ vs $78 \pm 34 \mathrm{~min} ; p=0.0002$ ).

The similar effects of gestation on overall glucose disposal (breakfast and dinner combined) and maximal postprandial plasma insulin concentrations are shown in Fig. 6. There were significant delays both for glucose disposal (early vs late gestation $R_{\mathrm{d}} t_{50 \%} 108$ [87-125] vs 135 [110-158] $\mathrm{min} ; p=0.005)$ and for peak postprandial plasma insulin concentration (early vs late gestation insulin $t_{\max } 49$ [37-55] vs 71 [52-108] $\left.\mathrm{min} ; p=0.004\right)$.

\section{Discussion}

We describe the first detailed physiological insights into carbohydrate metabolism, glucose turnover and insulin kinetics in pregnancy in women with type 1 diabetes. In the fasted state, glucose production and disposal rates were well matched in early and late gestation, with no differences between our study population and what had previously been described in healthy pregnancy [1]. In addition, we found no changes in glucose bioavailability or postprandial glucose appearance between early and late gestation. However, we found significant delays of approximately 30 min duration in postprandial glucose disposal during late gestation. This is likely to be due to slower achievement of a maximal postprandial plasma insulin concentration and increased peripheral insulin resistance, which together impede postprandial glucose uptake, facilitating more prolonged postprandial hyperglycaemia in late pregnancy.
A similar study using $\left[6,6-{ }^{2} \mathrm{H}_{2}\right]$ glucose and $\left[\mathrm{U}-{ }^{13} \mathrm{C}\right]$ glucose tracers in healthy pregnant women (seven in early and five in late gestation) was performed by Kalhan et al. [1]. After a prolonged fast (14 h), they also found increases in total gluconeogenesis but no changes in EGP or glucose disposal rates, when adjusted for maternal weight gain. Similarly, fasting plasma insulin concentrations were slightly higher, but not significantly so, in late gestation. Fasting plasma glucose concentrations were notably lower (3.6-4.2 mmol/1) compared with women with type 1 diabetes $(6.1 \mathrm{mmol} / \mathrm{l})$. Another study by the same investigators comprising ten pregnant women (five healthy, four with gestational diabetes and one with type 1 diabetes) at term suggested no differences in EGP between healthy controls and women with gestational diabetes [3]. These studies focused on gluconeogenesis during fasting conditions and did not evaluate postprandial glucose control. The computational methodology required for a more complex evaluation of postprandial glucose fluxes has been more recently available [26], thereby facilitating further insights into postprandial glucose control in type 1 diabetic pregnancy.

We have demonstrated an increasing, but potentially modifiable, mismatch between postprandial glucose appearance and glucose disposal in late gestation. Despite marked differences in meal composition (sugar-rich vs starch-rich) and meal timing (07:00 vs 18:00 hours), glucose disposal was similarly delayed in late pregnancy. The particularly rapid appearance of glucose after a sugar-rich breakfast exacerbated this mismatch $\left(R_{\mathrm{a}} t_{50 \%} 58 \pm 18 \mathrm{~min}\right.$ vs $\left.R_{\mathrm{d}} t_{50 \%} \quad 103 \pm 17 \mathrm{~min}\right)$, with the delay between glucose appearance and disposal of approximately $45 \mathrm{~min}$ in early pregnancy extended to $75 \mathrm{~min}$ in the third trimester $\left(R_{\mathrm{a}} t_{50 \%}\right.$ $52 \pm 33 \mathrm{~min}$ vs $\left.R_{\mathrm{d}} t_{50 \%} 125 \pm 21 \mathrm{~min}\right)$. As glucose disposal is insulin-mediated and larger prandial boluses were given in late pregnancy, this finding was unexpected and, to our knowledge, has not previously been reported.

The factors contributing to the slower development of maximal postprandial plasma insulin concentration in late pregnancy are unclear. Catalano et al. described increased insulin clearance in pregnancy, but we found no effect of gestation on the metabolic clearance rate of insulin [30]. In obese, non-pregnant individuals, delayed insulin absorption has been associated with large insulin doses and reduced subcutaneous adipose tissue blood flow [31, 32]. Sandqvist et al. reported impaired transport of insulin from the circulation to both adipose tissue and muscle in obese, insulin-resistant postmenopausal women [33]. Although the distribution of insulin to adipose tissue correlated with factors relevant to insulin resistance, the metabolic impact of impaired insulin delivery was unclear. The women in our study were not obese, they had only modest gestational weight gain (approximately $5.7 \mathrm{~kg}$ between study visits) and their prandial insulin boluses were not excessive for 
pregnancy. Microdialysis techniques would be required to confirm delayed absorption of insulin from subcutaneous tissues to the systemic circulation.

Although insulin resistance is a well-described phenomenon of advancing gestation, whether it occurs predominantly in the liver, peripheral tissues or both has not been established in pregnancy. We found significant consistent reductions in $S_{\text {I,PERI }}$, consistent across women despite their varying body weight and insulin requirements. In contrast to Catalano et al. [34], we also found consistent gestational increases in $R_{\mathrm{I} \text { EGGP. }}$ As maternal insulin resistance is a prime regulator of nutritional availability for the developing placenta and fetus, increased hepatic and peripheral insulin resistance may reflect normal and physiologically necessary adaptations in healthy pregnancy but contribute to fetal growth acceleration and a risk of large-for-gestational-age offspring in pregnancies complicated by type 1 diabetes.

Clinical and therapeutic implications Although we found no systematic changes in glucose bioavailability or postprandial glucose appearance over gestation, we did observe significant interindividual and intermeal variability in the rate of total carbohydrate absorption. The 'double peak' glucose appearance after dinner in early pregnancy is very similar to that recently described after a pasta meal in nonpregnant individuals [35], suggesting that it is a characteristic feature of meals rich in complex carbohydrates. This has clinical implications for advice given to women on the timing and frequency of postprandial glucose monitoring. Half of the post-breakfast glucose appeared after $1 \mathrm{~h}$ (breakfast $R_{\mathrm{a}} t_{50 \%} 58 \pm 18 \mathrm{~min}$ ) but took almost $2 \mathrm{~h}$ to do so after dinner (dinner $R_{\mathrm{a}} t_{50 \%} \quad 109 \pm 24$ mins). Testing $1 \mathrm{~h}$ after meals may capture peak postprandial glucose, in some women for some meals, but fails to capture the complexity of total carbohydrate absorption between different meals or different women. In practice, continuous glucose monitoring or repeated postprandial testing may be required for optimal insulin dose adjustment [36].

In non-pregnant individuals using CSII, the administration of prandial boluses $15 \mathrm{~min}$ before meals is associated with improved postprandial glycaemia [37]. Taken together with our findings, this suggests that the optimal timing for prandial insulin is $15 \mathrm{~min}$ before meals in early pregnancy and $30-40 \mathrm{~min}$ before meals in late pregnancy. As pregnancy advances, it may be appropriate to advise that women replace rapidly absorbed sugar-rich meals with more slowly absorbed starch-rich alternatives. Adjunctive pharmacological therapies such as pramlintide to suppress glucagon and delay gastric emptying, or $\alpha$-glucosidase inhibitors to decrease intestinal carbohydrate digestion, may also be beneficial [38], but these are not approved for use in pregnancy. Alternatively, pre-meal snack primers and/or postprandial physical activity, which enhance peripheral glucose uptake, may offer additional therapeutic options in late pregnancy [39].

We used closed-loop insulin delivery as the best available method for facilitating as near to steady-state fasting and pre-meal glucose levels as possible. However, it should be noted that there are typically no differences in the total insulin doses infused or plasma insulin concentrations during conventional CSII and closed-loop insulin delivery $[22,23]$. More work is needed to extend and validate our findings and to further evaluate the risks and benefits of earlier insulin administration in pregnancy in type 1 diabetes. Investigators should also seek to determine whether there are differences in insulin absorption according to the delivery method (CSII vs subcutaneous injection) or infusion site (abdomen vs flank or limbs), and whether our findings are specific to type 1 diabetes or applicable also to pregnant women with gestational and type 2 diabetes.

Important strengths of our study include the use of closed-loop insulin delivery to maintain steady-state glycaemic conditions, stable labelled isotopes to document glucose fluxes, standardised mixed meals with a variable dietary composition (a sugar-rich breakfast and a starch-rich evening meal) and advanced computational modelling methodology [26]. Triple tracer techniques allow discrimination between EGP and glucose appearance from meals containing glucose but not complex carbohydrates [40]. Our double tracer methodology is applicable for complex carbohydrates, has comparable postprandial measurement accuracy and benefits from reduced experimental and analytical complexity [41].

Unfortunately, we have no details of maternal body composition, lipids or fat-free vs adipose tissue mass. Although our observation of approximately $100 \%$ bioavailability of $\left[\mathrm{U}_{-}{ }^{13} \mathrm{C}\right]$ glucose is in line with previous observations [42-44], absorption of more slowly absorbed sugars (sucrose and fructose) is not necessarily assumed to be related to the absorption of the meal tracer. A limitation, of limited clinical significance, is that we were unable to separate EGP and glucose appearance from complex carbohydrates, which would have required intrinsic labelling of glucose in the starch [14]. The crucial clinically relevant information, is not how much of the postprandial glucose appearance is attributable to EGP vs meal-derived oral glucose, but rather the discrepancy between total postprandial glucose appearance and glucose disposal, which make up the postprandial glucose excursion.

In conclusion, the finding that postprandial plasma $t_{\max }$ concentration was significantly delayed in late gestation has clinical implications for the timing of insulin therapy, both in routine clinical care and in the development of closedloop algorithms. Administering prandial insulin boluses 30-40 min before meals may reduce the mismatch between 
glucose appearance and glucose disposal, attenuating postmeal hyperglycaemia in late pregnancy. These insights into the pathophysiology and management of postprandial hyperglycaemia may help women with type 1 diabetes to optimise their glycaemic control in late gestation.

Acknowledgements We are grateful to the research staff at the Wellcome Trust clinical research centre (Addenbrooke's Hospital, Cambridge, UK) for their excellent clinical care, J. Weston (Addenbrooke's Hospital, Cambridge, UK) for dietary support, J. Hayes (University of Cambridge Metabolic Research Laboratory, Cambridge, UK) for study coordination, N. Jackson and J. Batt (University of Surrey, Guildford, UK) for glucose enrichment measurements, P. Luzio and colleagues (University of Cardiff, Cardiff, UK) for plasma insulin measurements, and all the study participants for their generous and enthusiastic support. Data from this study were presented at the 2011 American Diabetes Association Meeting in San Diego and have been published in abstract form [45].

Duality of interest H.R. Murphy receives speaker honoraria from Minimed Medtronic; R. Hovorka receives speaker honoraria from Minimed Medtronic, Lifescan and Novo Nordisk, and serves on the Medtronic and Animas advisory panel; R. Hovorka, M.E. Wilinska have received licence fees from Becton Dickinson; and R. Hovorka and M.E. Wilinska have patent applications. The remaining authors declare there there is no duality of interest associated with this manuscript. The views expressed in this publication are those of the authors and not necessarily those of the NHS, the National Institute for Health Research or the Department of Health

Contribution statement HRM and RH designed the study with input into the study protocol from all authors. JA, JH, DS, RCT and GR recruited participants. JA, JH, DE and HRM performed the studies. AMU measured glucose enrichment. HRM drafted the manuscript, and all authors assisted with revising it critically for important intellectual content. All authors contributed to the analysis and interpretation of data and approved the final version.

\section{References}

1. Kalhan S, Rossi K, Gruca L, Burkett E, O'Brien A (1997) Glucose turnover and gluconeogenesis in human pregnancy. J Clin Invest 100:1775-1781

2. Murphy HR, Rayman G, Duffield K et al (2007) Changes in the glycemic profiles of women with type 1 and type 2 diabetes during pregnancy. Diabetes Care 30:2785-2791

3. Kalhan SC, D'Angelo LJ, Savin SM, Adam PA (1979) Glucose production in pregnant women at term gestation. Sources of glucose for human fetus. J Clin Invest 63:388-394

4. Baumann MU, Deborde S, Illsley NP (2002) Placental glucose transfer and fetal growth. Endocrine 19:13-22

5. Herranz L, Pallardo LF, Hillman N, Martin-Vaquero P, Villarroel A, Fernandez A (2007) Maternal third trimester hyperglycaemic excursions predict large-for-gestational-age infants in type 1 diabetic pregnancy. Diabetes Res Clin Pract 75:42-46

6. Kerssen A, de Valk HW, Visser GH (2007) Increased second trimester maternal glucose levels are related to extremely largefor-gestational-age infants in women with type 1 diabetes. Diabetes Care 30:1069-1074
7. Combs CA, Gunderson E, Kitzmiller JL, Gavin LA, Main EK (1992) Relationship of fetal macrosomia to maternal postprandial glucose control during pregnancy. Diabetes Care 15:1251-1257

8. Macintosh MC, Fleming KM, Bailey JA et al (2006) Perinatal mortality and congenital anomalies in babies of women with type 1 or type 2 diabetes in England, Wales, and Northern Ireland: population based study. BMJ 333:177

9. Persson M, Norman M, Hanson U (2009) Obstetric and perinatal outcomes in type 1 diabetic pregnancies: a large, population-based study. Diabetes Care 32:2005-2009

10. Evers IM, de Valk HW, Visser GH (2004) Risk of complications of pregnancy in women with type 1 diabetes: nationwide prospective study in the Netherlands. BMJ 328:915

11. Weiss PA, Scholz HS, Haas J, Tamussino KF, Seissler J, Borkenstein MH (2000) Long-term follow-up of infants of mothers with type 1 diabetes: evidence for hereditary and nonhereditary transmission of diabetes and precursors. Diabetes Care 23:905-911

12. Clausen TD, Mathiesen ER, Hansen T et al (2008) High prevalence of type 2 diabetes and pre-diabetes in adult offspring of women with gestational diabetes mellitus or type 1 diabetes: the role of intrauterine hyperglycemia. Diabetes Care 31:340346

13. Rijpert M, Evers IM, de Vroede MA, de Valk HW, Heijnen CJ, Visser GH (2009) Risk factors for childhood overweight in offspring of type 1 diabetic women with adequate glycemic control during pregnancy: nationwide follow-up study in the Netherlands. Diabetes Care 32:2099-2104

14. Priebe MG, Wachters-Hagedoorn RE, Heimweg JA et al (2008) An explorative study of in vivo digestive starch characteristics and postprandial glucose kinetics of wholemeal wheat bread. Eur J Nutr 47:417-423

15. Taylor R, Magnusson I, Rothman DL et al (1996) Direct assessment of liver glycogen storage by $13 \mathrm{C}$ nuclear magnetic resonance spectroscopy and regulation of glucose homeostasis after a mixed meal in normal subjects. J Clin Invest 97:126-132

16. Basu R, Dalla Man C, Campioni M et al (2006) Effects of age and sex on postprandial glucose metabolism: differences in glucose turnover, insulin secretion, insulin action, and hepatic insulin extraction. Diabetes 55:2001-2014

17. Pehling G, Tessari P, Gerich JE, Haymond MW, Service FJ, Rizza RA (1984) Abnormal meal carbohydrate disposition in insulindependent diabetes. Relative contributions of endogenous glucose production and initial splanchnic uptake and effect of intensive insulin therapy. J Clin Invest 74:985-991

18. Pennant ME, Bluck LJ, Marcovecchio ML, Salgin B, Hovorka R, Dunger DB (2008) Insulin administration and rate of glucose appearance in people with type 1 diabetes. Diabetes Care $31: 2183-2187$

19. Woerle HJ, Albrecht M, Linke R et al (2008) Impaired hyperglycemia-induced delay in gastric emptying in patients with type 1 diabetes deficient for islet amyloid polypeptide. Diabetes Care 31:2325-2331

20. Chiloiro M, Darconza G, Piccioli E, de Carne M, Clemente C, Riezzo G (2001) Gastric emptying and orocecal transit time in pregnancy. J Gastroenterol 36:538-543

21. National Institute for Health and Clinical Excellence. Diabetes in Pregnancy (2008) Management of diabetes and its complications in pregnancy from the pre-conception to the postnatal period. NICE Guideline 63. Available from www.nice.org.uk. Accessed 31 March 2011

22. Murphy HR, Elleri D, Allen JM et al (2011) Closed-loop insulin delivery during pregnancy complicated by type 1 diabetes. Diabetes Care 34:406-411

23. Hovorka R (2011) Closed-loop insulin delivery: from bench to clinical practice. Nat Rev Endocrinol 7:385-395 
24. Hovorka R, Shojaee-Moradie F, Carroll PV et al (2002) Partitioning glucose distribution/transport, disposal, and endogenous production during IVGTT. Am J Physiol 282:E992-E1007

25. Shojaee-Moradie F, Jackson NC, Jones RH, Mallet AI, Hovorka R, Umpleby AM (1996) Quantitative measurement of 3-O-methyl-Dglucose by gas chromatography-mass spectrometry as a measure of glucose transport in vivo. J Mass Spectrom 31:961-966

26. Hovorka R, Jayatillake H, Rogatsky E, Tomuta V, Hovorka T, Stein DT (2007) Calculating glucose fluxes during meal tolerance test: a new computational approach. Am J Physiol 293:E610 E619

27. Lunn DJ, Thomas A, Best N, Spiegelhalter D (2000) WinBUGS - a Bayesian modelling framework: concepts, structure, and extensibility. Stat Comput 10:325-337

28. Mari A (1992) Estimation of the rate of appearance in the nonsteady state with a two-compartment model. Am J Physiol 263: E400-E415

29. Wilinska ME, Chassin LJ, Schaller HC, Schaupp L, Pieber TR, Hovorka R (2005) Insulin kinetics in type-I diabetes: continuous and bolus delivery of rapid acting insulin. IEEE Trans Biomed Eng 52:3-12

30. Catalano PM, Drago NM, Amini SB (1998) Longitudinal changes in pancreatic beta-cell function and metabolic clearance rate of insulin in pregnant women with normal and abnormal glucose tolerance. Diabetes Care 21:403-408

31. Vora JP, Burch A, Peters JR, Owens DR (1992) Relationship between absorption of radiolabeled soluble insulin, subcutaneous blood flow, and anthropometry. Diabetes Care 15:14841493

32. Gagnon-Auger M, du Souich P, Baillargeon JP et al (2010) Dose-dependent delay of the hypoglycemic effect of shortacting insulin analogs in obese subjects with type 2 diabetes: a pharmacokinetic and pharmacodynamic study. Diabetes Care 33:2502-2507

33. Sandqvist M, Strindberg L, Schmelz M, Lonnroth P, Jansson PA (2011) Impaired delivery of insulin to adipose tissue and skeletal muscle in obese women with postprandial hyperglycemia. J Clin Endocrinol Metab 96:E1320-E1324
34. Catalano PM, Huston L, Amini SB, Kalhan SC (1999) Longitudinal changes in glucose metabolism during pregnancy in obese women with normal glucose tolerance and gestational diabetes mellitus. Am J Obstet Gynecol 180:903-916

35. Elleri D, Harris J, Kumareswaran K et al (2010) Glucose appearance of large slowly-absorbed evening meal containing complex carbohydrates (CHO) in type 1 diabetes (T1D). Diabetologia 53:S272

36. Murphy HR, Rayman G, Lewis K et al (2008) Effectiveness of continuous glucose monitoring in pregnant women with diabetes: randomised clinical trial. BMJ 337:a1680

37. Luijf YM, van Bon AC, Hoekstra JB, Devries JH (2010) Premeal injection of rapid-acting insulin reduces postprandial glycemic excursions in type 1 diabetes. Diabetes Care 33:2152-2155

38. Lebovitz HE (2010) Adjunct therapy for type 1 diabetes mellitus. Nat Rev Endocrinol 6:326-334

39. Chen MJ, Jovanovic A, Taylor R (2010) Utilizing the secondmeal effect in type 2 diabetes: practical use of a soya-yogurt snack. Diabetes Care 33:2552-2554

40. Basu R, Di Camillo B, Toffolo G et al (2003) Use of a novel triple-tracer approach to assess postprandial glucose metabolism. Am J Physiol 284:E55-E69

41. Haidar A, Elleri D, Allen JM et al (2010) Triple tracer (TT) and double tracer (DT) techniques are reliable methods to estimate glucose appearance in type 1 diabetes. Diabetologia 53:S271

42. Ferrannini E, Bjorkman O, Reichard GA Jr et al (1985) The disposal of an oral glucose load in healthy subjects. A quantitative study. Diabetes 34:580-588

43. Mari A, Wahren J, DeFronzo RA, Ferrannini E (1994) Glucose absorption and production following oral glucose: comparison of compartmental and arteriovenous-difference methods. Metab Clin Exp 43:1419-1425

44. Livesey G, Wilson PD, Dainty JR et al (1998) Simultaneous timevarying systemic appearance of oral and hepatic glucose in adults monitored with stable isotopes. Am J Physiol 275:E717-E728

45. Murphy HR, Elleri D, Allen J et al (2011) Changes in glucose turnover during pregnancy in women with type 1 diabetes. Diabetes 60:A54 